\title{
Knowledge Management in Academic Library: A need based approach
}

\author{
Ram Kumar Pathak
}

\section{Introduction:}

The knowledge has been recognized as the driver of productivity and economic growth in the knowledge-based economy. Countries around the globe are reviewing and restructuring regulations, financial operations and ownership in an attempt to take advantage of knowledge economy. In this economy there is a gradual shift from material goods to intangible goods. Stewart $(\mathbf{1 9 9 7})^{1}$ highlighted the importance of knowledge when he stated "Knowledge has become the primary ingredient of what we make, do, buy and sell. As a result, managing it - finding and growing intellectual capital, storing it, selling it, sharing it - has become the most important economic task of individuals, business and nations ". In July 1999, Tony Blair, the British Prime Minister said "the knowledge economy is the economy of future ". The Government of India has also realized the importance of knowledge economy and established the national knowledge commission that has identified knowledge as new determinants to increase India's competitive advantage in the field of knowledge. It has also realized the importance of libraries and library professionals and asked them to facilitate inclusive society where "Knowledge is Power" is accessible to all. What significantly add value and contributes to competitive advantage in the knowledge era is the ability to manage knowledge within the organization.

The recognition of knowledge as the driver of productivity and economic growth leads to new focus on the role of information and knowledge professionals. This recognition not only occurs in business organization but also in non-profit organization such as academic libraries.

The management of information and knowledge has long been regarded as the domain of librarians and libraries as the information and knowledge are basic stock- in -trade for libraries.

Obviously, the application of knowledge management to libraries assumes greater significance and this is particularly true for Academic libraries, as these libraries will face unprecedented challenges in the 21st century. The changing environment of academic life demands new competencies in academic librarians (Mahmood, $2003)^{2}$.

Also, the knowledge and expertise of academic librarians needs to be seen as library's greatest asset. Since librarians have been managing knowledge from time immemorial (Butler 2000. P.40 $)^{3}$ and academic librarians, particularly, University librarians are equipped with rich research information and skills; hence they may stake their claim as their organization's best-qualified knowledge managers.

The traditional functions of Academic libraries is to collect, process, disseminate store and retrieve information to provide better services to the end users. But in the increasingly changing environment, the operation of academic library has become more challenging which demands new method of managing information and knowledge. There has been a paradigm shift in libraries from an information management to knowledge management.

The concept of Knowledge management in libraries as a completely new method of management demands change in its conventional management.

Academic libraries with the conventional functions to collect, process, disseminate, store and utilize information to provide services to its users now need to improve the services provided to the academic community by becoming an learning organization that enhance the process of managing knowledge and innovation. The role of librarians need to be shifted form information provides to knowledge mangers and therefore they need to constantly update or acquire new skills and knowledge.

Foo, et al (2002) ${ }^{4}$ pointed out that academic librarian as knowledge seeker need to play active roles in searching for innovative solutions to the issues involved in adapting new environments.

\section{A research agenda:}

Knowledge management is a viable and effective management tool by which academic libraries can improve their operational efficiency and knowledge products and services. It is conscious strategy of providing right knowledge to the right user at the right time with a right expense of financial and human resources. Knowledge management needs to be focused on effective research in the context of Academic libraries. 
Therefore, this study has been taken. The main focus of this study is to examine the role of academic libraries with regard to knowledge management and it is suggested through this paper that organization like academic library whose activities are mostly information based needs to be engaged in knowledge management practices and the libraries which are not engaged in some sort of knowledge management practices should act now. This paper is an attempt to address the following basic questions:

(i) Why knowledge management is important and required in academic libraries?

(ii) What is the expected benefit of knowledge management in academic libraries?

(iii) How knowledge is created and managed?

(iv) How to gain competitive advantage by effective implementation of knowledge management?

(V) What is a staffing implication for introducing knowledge management in academic libraries?

\section{Genesis of knowledge management:}

As early as in 1965, Peter Drucker 5 pointed out that "Knowledge" would replace land, labor, capital machine etc. to become the chief source of production. In $1991^{6}$ Ikujiro Nonaka proposed the concept of tacit and explicit knowledge. With dawn of knowledge- based economy knowledge has been realized as new determinants of competitive advantage. Organizational knowledge is being recognized as significant source of competitive advantage across the globe in the business world. Managing knowledge is a complex organizational issue which is fundamentals for success in the new economy Dalkir ${ }^{7}$ (2005). Undoubtedly, knowledge management has become the most important phenomenon for most of the economies of the world in the recent decades.

Like many of today's organization, libraries can be regarded as a system of integrative process that work together in order to achieve overall organizational goals. Knowledge management is as important for libraries as for business minus the competitive proprietary, and money making concerns.

University libraries are the reservoir of knowledge and information and academics are the best knowledge creators. As a learning organization it is now the time for academic libraries to reposition themselves in a central stage of and as a leading player of knowledge management. Thus, journey of "Knowledge management" was started and popularized in the business world, much touted and hyped since late 1990s and it has emerged as an important tool for increasing the operational efficiency of the organization and the same can be applied in the library world also.

\section{Concepts of Knowledge management: from data to knowledge:}

One of the main concerns in knowledge management is the conceptualization of knowledge. For this it is important to provide a few brief operational definition of key terms used throughout this paper. For the purpose of this article following key terms have been defined:

(i) Data : Data is a set of discrete facts about events and is considered raw facts and figure that must be further processed to become information

(ii) Information: Information is processed Data.

(iii) Knowledge: Knowledge is a fluid mix of framed experience, values, contextual information, and expert insight that provides a framework for evaluating and incorporating new experiences and information. (Davenport and Prusak, 1998) ${ }^{8}$.

(iv) Explicit Knowledge: It is the knowledge found in books, documents, databases, e-mail and the like. It is public Knowledge rather than private.

(v) Tacit (implicit) knowledge: Implicit knowledge is difficult to capture and communicate. It is Private knowledge. It is personal knowledge stored in the mind of the individuals. Tacit knowledge is job or task specific and related to context (Crowley, 2001).

(vi) Organizational Knowledge: what an organization knows, how it uses what it knows, how fast it can know something new (Prusak, 1997). ${ }^{10}$

(vii) Organizational memory: explicit, disembodied, persistent representation knowledge Information in the organization (Liebowitz and Beckman, 1998) ${ }^{11}$.

(viii) Knowledge management: "It is the explicit and systematic management of vital knowledge and its associated process of creating, gathering, organizing, diffusion, use and exploitation. It requires turning personal knowledge into corporate knowledge that can be widely shared throughout an organization and appropriately applied" (Skryme, 1997) ${ }^{\mathbf{1 2}}$.

Knowledge management deals with people, culture and technology to enable organizations to achieve strategic objectives.

\section{Knowledge management in academic libraries:}

As a learning organization academic libraries are expected to provide strong leadership in knowledge management. They need to improve their knowledge management in all the key areas of library services. Some 
of articles on knowledge management dealt with the operation of the technical services. (Turvey and Letarte (2002) $)^{13}$ argue that" the library world is characterized by fast-paced change, and perhaps no other area as much as field of cataloguing and they tried to define cataloguing as very important aspect of knowledge management in as increasingly digital world.

The availability of information in multiple and varied formats, new means and methods of the delivery of information in the networked environments, emphasis on self-directed, independent study, student- centered learning, modularization in teaching and learning pattern, changes in organization structure etc. are the major issues and concerns which urges the academic librarian to implement the knowledge management. Library needs to use new approach to capture web information by cooperative efforts such as Dublin core and metadata and the cooperative online resource catalogue.

Going beyond explicit knowledge library is expected to develop mechanism to capture all the tacit knowledge know-how of library staff should be valued and shared. Jantz $(2001, p .35)^{14}$ had pointed out that in many library settings there is no systematic approach to organizing the

Knowledge of enterprise, and making it available to other librarian and staff in order to improve the library.

Hence, libraries and librarians are expected to gear up themselves for the successful implementation knows management initiatives to address above mentioned issues.

\section{Principles of Knowledge Management:}

Thomas H. Davenport ${ }^{15}$ formulated ten (10) principles of knowledge management as stated below:

(i) Knowledge management is expensive (but so is stupidity!)

(ii) Effective management of knowledge requires hybrid solutions involving both people and technology.

(iii) Knowledge management is highly political.

(iv) Knowledge management requires knowledge managers.

(v) Knowledge management benefits more from maps than models, more from markets than hierarchies.

(vi) Sharing and using knowledge are often unnatural acts.

(vii) Knowledge management means improving knowledge work processes.

(viii) Access to knowledge is only the beginning.

(ix) Knowledge management never ends.

(x) Knowledge management requires a knowledge contract.

\section{Objectives of knowledge management in Academic libraries:}

The main objectives of knowledge management in academic libraries are as follows:-

(i) To promote collection, processing, storage and storage and distribution of knowledge.

(ii) To promote scientific research.

(iii) To promote relationship between library and users

(iv) To protect the intellectual property right, in IT era

(v) To create knowledge repositories and manage knowledge as an asset

(vi) To organize the value of knowledge and improve effective research

\section{Need /importance of knowledge management in Academic libraries:}

Some of the specific factors that stress the need of knowledge management academic libraries are as follows:

(i) Knowledge being the strategic and key resource of an organization likes academic libraries.

(ii) The threat of being marginalized by internet based information services and students and faculty's own information gathering efforts.

(iii) To fulfillment of dream of library professionals and mission of the academic libraries and their parent institution, that is, to provide right knowledge at the right time to the right person in the right format.

(iv) Reduction in staff and budget need to replace informal knowledge with formal methods.

(v) Quitting job by potential workforce lead to loss of valuable organizational knowledge.

(vi) Reduced budget, increased demand from the faculty and students and greater expectation from higher administration. 
(vii) Products and services are increasingly becoming complex and they demand new skill set and competency

(viii) Technological advancement and rate of innovation is rising.

(ix) The need for lifelong learning is an inescapable reality.

\section{Expected benefits of implementation of Knowledge management in academic libraries:}

Following are the benefits that can be derived from knowledge management:

(i) Better coverage of resources and capabilities

(ii) Better staff utilization.

(iii) Higher quality of deliverables.

(iv) Just in time, performance centered learning and training.

(v) Collaboration at the norm (no disincentives for collaboration)

(vi) More user engagements and interactions, both with internal users and with the library's external users, clients, customers and stakeholders.

(vii) Improved customers/ users/staff satisfaction.

(viii) Increased libraries operational efficiency and cater to the ever increasing needs of the users.

(ix) Improvement in efficiency and effectiveness of technical services.

\section{Process of knowledge creation and management in academic libraries:}

The knowledge in the context of academic libraries may be of the following Types:

(i) The knowledge of library's operation

(ii) The knowledge of library users

(iii) The knowledge of library collection

(iv) The knowledge of library facilities and technologies available

By putting together these type of know ledges new knowledge can be created. Furthermore, the creation of new knowledge is guided by two factors: - (i) Creativity \& (ii) innovation.

Knowledge creation refers to the ability to originate novel and useful ideas and solutions.

It focuses on the developments of new skills, new products, better ideas and more efficient processes. The much knowledge is stored in the heads of the people. Therefore creating knowledge academic libraries need to develop and devise the system to bring out the creativity and innovation from library staff. Brainstorming can be one of the methodologies to bring out creativity and innovation from individuals. The process of brainstorming makes possible the sharing the views and ideas and mental modes commonly used by individuals. Different individuals have different levels of knowledge about same thing as well as different ways of looking at the same thing. When an academic library as an organization knows what it knows, values and prioritizes that knowledge and develop systems for leveraging and sharing, it leads directly to creation of knowledge.

Tacit knowledge invariably resides with the individuals and has to be in first place transferred to the organization. No organization including academic libraries able to create knowledge without the active initiatives of the individuals within it. Organization wise dialogues, discussions, experience sharing and observation can help in disseminating explicit individual knowledge among all in the organization and, therefore, create 'organizational knowledge'.

\section{Process of Knowledge creation:}

According to Soo et al. (2002) ${ }^{\mathbf{1 6}}$ the knowledge creation process can be defined in three ways, i.e. sourcing of information, know-how from internal and external network, internalizing and integrating the information and applying it.

Also, P. Galagan ${ }^{17}$ proposed the following knowledge management process:

(i) Generating new knowledge

(ii) Accepting knowledge from external sources

(iii) Representing knowledge in documents, databases and so on.

(iv) Embedding knowledge in processes, products and services

(v) Transferring existing knowledge

(vi) Using accessible knowledge in decision making

(vii) Facilitating knowledge through culture and incentives

(viii) Measuring the value of knowledge assets and the impact of knowledge management 
Further, The SECI (i.e. Socialization, Externalization, Combination and internalization) model of NONAKA and TAKAUCHI (1995) ${ }^{18}$ is widely accepted model of knowledge creation which can be applied in academic libraries, too.

For NONAKA and KONNO (1998) ${ }^{19}$ organizational knowledge creations are a continuous and a dynamic interaction between tacit and explicit knowledge which can be pictorially represented as follows:

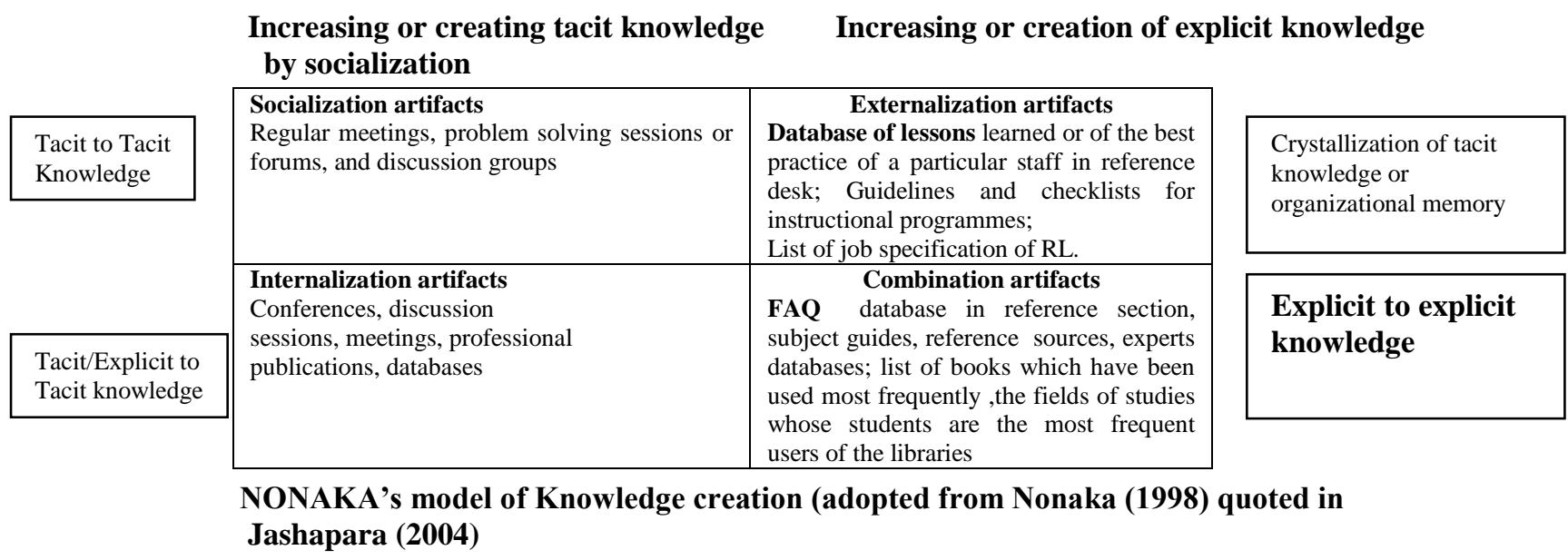

Socialization is the conversion of tacit knowledge into tacit knowledge and it starts with sharing of tacit knowledge between individuals and learning from each other. The interaction among information resources ,users and librarians their knowledge transferred from one librarian to another through regular formal/informal meetings, problem solving sessions, forums, discussions, various social medias, and so on. The different ICT technologies such as e-mail, networking, software like team viewer, etc facilitates such interactions. In absence of such sharing activities librarians will have no option but to rely on their own expertise and personal knowledge.

Externalization deals with the process of conversion of tacit knowledge into explicit knowledge. According to NONAKA (1994) ${ }^{20}$ it is crystallized tacit knowledge. Metaphors, analogies, figures, models etc are used to communicate tacit knowledge. In the context of libraries examples of this are a database of lesson learned, best practices of a particular staff in reference desk, results of a problem solving, brainstorming meeting etc. Guidelines for planning and running instructional programmes can also be a crystallized form of experiences of librarians. These guidelines are structured tacit knowledge that are documented and have become available for all librarians including the new and inexperienced staff. The job specification of reference librarians, list of hints to teach effectively, and keys for reference interviews are the additional examples of this. The tacit-toexplicit knowledge can be referred as organizational memory.

Combination refers to the conversion of explicit knowledge to explicit knowledge. It involves systematizing and combining explicit knowledge through meetings, documents, telephonic conversations, or through computer networks. Accumulation from different sources and reconfiguration of existing information generates new explicit knowledge. Frequently Asked Questions (FAQ) databases created by reference staff, subject guides, list of reference sources, experts' databases, and the revised guidelines are the some examples of combination in the library context.

Internalization is the conversion of explicit knowledge into tacit knowledge. It is the process of transforming individual learning and memory into organizational learning and memory. In this mode of conversion knowledge created through experience, clear documentation, manuals. Oral stories are stored in the mind of the peoples of the organization. Reading about and listening to others experiences may generate adequate interest in the knowledge consumers (users and staff) and facilitate tacit knowledge generation. Previous knowledge can be corrected or modified and new knowledge is created within the learners' mind. Conferences, discussion sessions, meetings, and professional publications are some examples that provide opportunities for the librarians to analyze and assess their knowledge and increase their thinking abilities and to create new knowledge.

Creating competitive advantage in academic library by effectively implementing/managing knowledge: 
Knowledge management can provide competitive advantage to organization through either

(i) Helping them implement a new strategy that was not possible otherwise

(ii) Helping them implement their regular / existing strategies more efficiently and effectively (than their competitors).

(iii) Embedding knowledge in their products, services or information offerings, or

(iv) Enhancing the efficiency of their non-strategic processes (Davenport, 1999) ${ }^{\mathbf{2 1}}$.

The organization may gain competitive advantage by focusing on either all of them, or a select few of them, depending on their intent and context. This linkage of knowledge management to strategy formulation will help organization leverage knowledge as a fundamental basis of competition.

Academic libraries need to focus on developing dynamic capabilities, rather than just core capabilities (to sustain their competitive advantage over a longer horizon) to remain relevant over a longer horizon.

Implementation of knowledge management is more than a project. The successful implementation of knowledge management requires foresight and planning. Since the organization of knowledge has always rested strongly with librarians, it is they, who must not only engage in, but also actively spearhead, knowledge management initiatives (Gandhi, 2004) 22 $^{22}$

\section{Organizational/ Staffing Implications:}

The success of academic libraries depends on the capabilities and skills of its staff to serve the needs of academic community more efficiently and effectively. Teng and Hawamdeh $(\mathbf{2 0 0 2}, \mathbf{P . 1 9 5})^{\mathbf{2 3}}$ identified the skills needed by information professionals in a knowledge-based environment:

(I) IT literacy

(II) A sharp and analytical mind

(III) Innovation and inquiring

(IV) Enables knowledge creation, flow and communication within organization and between staff and public.

Implementing knowledge management requires a change in behavior and mindset of working professionals in the academic libraries. A well coordinated approach with clear accountability for overall implementation is a key to success. Knowledge management is resource intensive and its impact on productivity takes time to start. Therefore, it is essentials academic librarians to update their skills constantly.

\section{Conclusion:}

This study presents a short description of emerging issues and implementation of knowledge management in academic libraries. The environment in which academic libraries operate is changing and it is essential for librarians to realize the potential of knowledge management and library managers need to prepare themselves to implement knowledge management to increase the operational efficiency of academic libraries. But, implementation of knowledge management requires foresight and planning and its success largely depends on the organizational culture. It requires a holistic and multidisciplinary approach to management process. It is the high time for librarians to reposition themselves in the central stage of and as a leading player in knowledge management.

\section{Bibliography:}

[1]. Butler, Y. (2000). Knowledge Management: If only you knew what you know. Australian LibraryJournal, vol.49, 31-42. [*3]

[2]. Crowley, Bill. (2001). Tacit knowledge, Tacit ignorance, and the future of Academic librarianship. Conference on knowledge management for academic librarians sponsored by Domnican University's centre for knowledge management. [*9]

[3]. Drucker, Peter. (1993). Post-capitalism society. Oxford, Great Britane: Butterworth-Heinmann.[*10]

[4]. Dalkir, Kimiz, (2005). Knowledge Management in theory and practice. London: Elsevier.[*7]

[5]. Davenport, T. and Prusak, L. Working knowledge: How organizations manage what they know. Cambridge, MA: Harvard University Press. [*8]

[6]. Davenport, Thomas H. (1996). Some Principles of Knowledge Management: More than ever, companies are realizing that their real advantage lies in what they know. But how do you manage knowledge. Accessed at http://www.strategybusiness.com/archives/?issue $=8549$. [*15]

[7]. Davenport, T.H. (1999). Knowledge management and the broader firm: strategy, advantage and performance. In Liebowitz, J. (ed.). Knowledge management handbook, Boca, Raton: CRC press: 2-1 to 2-11. [*21]

[8]. Foo, S., Chaudhry, A. S., Majid, S. M. and Logan, E. (2002). Academic libraries in transition: challenges ahead. Proceedings of the world library summit, Singapore: $22-26 .[* 4]$

[9]. Galagan, P. (1997). Smart companies (Knowledge Management). Training and Development, vol.51 (12), 20-25. [*17]

[10]. Gandhi, S. (2004). Knowledge management and reference services. The journal of Academic librarianship. Vol.30 (5), 368-381. [*22] 
[11]. Jantz, R. (2001). Knowledge management in academic libraries: special tools and processes to support information professional. Reference Services Review, vol. 29(1), 33-39.[*14]

[12]. Liebowitz, J. and Beckman, T. (1998). Knowledge organization: what every manager should know, Boca, Raton: St. Lucie Press. [*11]

[13]. Mahmood, K. (2003). A comparison between needed competencies of academic libraries and LIS curricula in Pakistan. The Electronic Library, vol. 21(2), 99-109.[*2]

[14]. Nonaka, Ikujiro. (1991). The Knowledge-creating Company. Harvard Business Review (Nov. - Dec. 1991), 96-99.[*6]

[15]. Nonaka, I. and H. Takeuchi. (1995). the knowledge-creating company: How Japanese companies create the dynamics of innovation. Newyork: Oxford University Press. [*18]

[16]. Nonaka, I., Konno,Noboru.(1998). The concept of Ba: building a foundation for knowledge creation. California management Review.vol.40 (3), 1-15. [*19]

[17]. Nonaka, I. (1994). A dynamic theory of organizational creation. Organization Science.vol.5 (1), 14-37.[*20]

[18]. Prusak, L. (1997). Introduction to knowledge in organization. In Prusak, L. (ed.), knowledge in organization, Boston: Butterw orthHeinmann.[*10]

[19]. Stewart, T. A. (1997). Intellectual Capital: The new wealth of organization. Newyork: Doubleday/ Currency. [*1]

[20]. Skyrme, D. (1997). Knowledge management: making sense of oxymoron. Web page ref: http://www.skyrme.com/insights/22km.htm.[*12]

[21]. Soo,C.W., Devinney, T.M., Midgley,D.F. and Deering, A.(2002). Knowledge Management: philosophy,pitfalls and processes. California Management Review.vol.44 (4), 129-150. [*16]

[22]. Turvey, M.R. and Letarte, K.M. (2002). Cataloguing or knowledge management: perspective of library educators on cataloguing education for entry level academic librarians. Cataloguing and Classification Quarterly, vol. 34(1/2), 165-87. [*13]

[23]. Teng,S. and Hawamden, S.(2002). Knowledge management in public libraries. ASLIB Proceedings.vol.54 (3), 188-197. [*23]

Note: Number marked as * in square bracket [ ] indicates the sequence of cited author in the article. 